\title{
TRANSICIÓN DEL VIRREINATO A LA REPÚBLICA: CALEIDOSCOPIO SOCIOPOLÍTICO-ECONÓMICO DEL ALTIPLANO PUNEÑO EN LA INDEPENDENCIA DE PERÚ (1815-1825)
}

\author{
TRANSITION OF THE VIRREINATO TO THE REPUBLIC: SOCIO-POLITICAL- \\ ECONOMIC KALEIDOSCOPE OF THE PUNEÑO ALTIPLANO \\ IN INDEPENDENCE OF PERU (1815-1825)
}

Jesús Wiliam Huanca-Arohuanca* y Néstor Pilco Contreras**

\begin{abstract}
La Independencia de Perú fue un proceso de guerra civil iniciado en la primera década del siglo XIX, afianzado con la rebelión del Cusco de 1814 e influido por la invasión napoleónica a España que finalizó en Ayacucho de 1824. Durante ese trayecto, la Intendencia del altiplano puneño fue el último reducto realista del virreinato del Perú y fue escenario de batallas importantes como Umachiri (1815) y Zepita (1823). El estudio tuvo como objetivo analizar la situación sociopolítico-económico del altiplano durante el proceso de Independencia. Empleándose el análisis documental y las guías de investigación, la información se organizó diacrónicamente según las unidades de estudio. Por tanto, los resultados develaron en el aspecto social que, la revolución del Cusco y las expediciones argentinas al Alto Perú, demandaron gran contingente de milicias indígenas para el ejército realista, ocasionando el descenso demográfico de la población puneña. En el aspecto económico, el aporte cambiario obligatorio de indígenas fue fundamental para sostener al ejército realista que causó una crisis generalizada. Mientras a nivel político, Puno, siendo una zona estratégica y último baluarte realista, fomentó la presencia de las principales autoridades realistas/patriotas en una guerra por la hegemonía y la libertad.
\end{abstract}

Palabras claves: Independencia, revolución, historia, altiplano, República.

The Independence of Peru was a process of civil war initiated in the first decade of the XIXth century, strengthened with the rebellion of the Cusco of 1814 and influenced by the Napoleonic invasion to Spain that finished in Ayacucho of 1824. During this trajectory, the Puneño altiplano intendency was the last realistic redoubt of the Viceroyalty of Peru and was the scene of important battles such as Umachiri (1815) and Zepita (1823). The study took as a target to analyze the socio-political-economic situation of the altiplano during the Independence process. Theinformation was organized diachronically according to the study units. Therefore, the results unveiled in the social aspect that, the revolution of the using documentary analysis and research guides Cusco and the Argentine expeditions to High Peru, demanded a big contingent of indigenous militias for the realistic army, causing the demographic descent of the puneñapopulation. On the economic side, the mandatory exchange rate of indigenous people was instrumental in sustaining the realistic army that caused a widespread crisis. While at a political level, Puno being a strategic area and last realistic bastion, the presence of the leading authorities encouraged realists / patriots in a war for hegemony and freedom.

Key words: Independence, revolution, history, altiplano, Republic.

\section{Introducción}

En la actualidad, el argumento de que una coyuntura de guerra sirve para apreciar los intereses y las motivaciones de los grupos sociales involucrados en ella, resulta clave para el estudio de los procesos de Independencia en América Latina (Morán y Carcelén 2019). En ese sentido, el presente estudio se enmarca dentro de la historia decimonónica como proceso sangriento, que según las conclusiones de
Méndez (2014) y Loayza (2016), fue sin duda una guerra civil liderada fundamentalmente por los criollos, quienes según sus intereses políticos y afanes personales de prestigio militar, participaron en el bando patriota y realista.

Desde inicios del siglo XX se desarrollaron tres posturas respecto del proceso de Independencia. La primera, es la tesis nacionalista, conocida en la historiografía nacional como la Independencia conseguida. Postura que sostiene a la Independencia como

\footnotetext{
* Departamento de Filosofía y Humanidades, Universidad Nacional de San Agustín de Arequipa. Arequipa, Perú.

Correo electrónico: jhuancaar@unsa.edu.pe

** Departamento de Ciencias Sociales, Universidad Nacional de San Agustín de Arequipa. Arequipa, Perú.

Correo electrónico: nepcer@gmail.com
} 
producto de la toma de conciencia colectiva, donde todos los sectores sociales luchan sin antagonismos por la emancipación bajo el liderazgo de los criollos (De la Puente, 1970). Asimismo, durante la década de 1970 surgió otra interpretación que aceptaba que la Independencia tuvo raíces internas, ya que incidía en el liderazgo indígena y mestizo, interpretación que fue favorecida por el gobierno nacionalista de Juan Velasco Alvarado, quien elevó a Túpac Amaru II a la categoría de héroe nacional y símbolo principal de la Independencia (Méndez, 2014).

Entre los años setenta y ochenta del siglo pasado se gestó la segunda visión o interpretación: la Independencia concedida. Esta postura sostiene que la Independencia fue producto de las corrientes libertadoras lideradas por San Martín y Simón Bolívar, es decir, fue traída desde afuera (Bonilla, 2016). Dicha tesis, que generó encendidos debates, fue presentada en un artículo publicado en 1972 por Heraclio Bonilla y Karen Spalding, quienes argumentaban que los criollos nunca estuvieron convencidos de la necesidad de independizarse y que los indios tampoco pudieron ser agentes activos en el proceso de Independencia (Bonilla y Spalding, 1981).

La tercera interpretación se desarrolló a finales del segundo milenio, poniendo énfasis en los aspectos políticos de la revolución hispánica. En este nuevo revisionismo historiográfico, la visión se conoce como la Independencia concebida (O'Phelan, 1987; 2014;. Escanilla, 2013; 2018), tesis que tiene como argumento esencial los numerosos cambios administrativos, económicos y políticos en el virreinato del Perú por la invasión francesa a España (Escanilla, 2018).

Hasta ahí, todas las interpretaciones historiográficas acerca de la Independencia responden a visiones sesgadas limeño-centristas. De manera que la tradición impuesta hace que se celebre el 28 de julio de 1821 la proclama de San Martín en Lima como día de la Independencia de Perú (HuancaArohuanca y Pilco, 2021). En consonancia, para Cecilia Méndez (2014) representa un hecho pacífico que no fue ni el comienzo ni el final de las guerras de Independencia; porque el escenario geográfico principal de aquellas guerras fue la sierra de Perú, teniendo hechos significativos como el primer grito de libertad liderado por Francisco de Zela en Tacna (1811), la primera junta de gobierno peruano en Huánuco (1812) y la revolución del Cusco (1814) liderado por los hermanos Angulo y Pumacahua. De manera que, con mayores probabilidades, quizá sea la tesis con mayor aceptación dentro de la comunidad académica histórica en el Perú de hoy.

Ahora bien, durante las operaciones militares, el sector social más vulnerable y protagonista a la vez recae en los indígenas, quienes lucharon según las circunstancias obligadas bajo el bando patriota o realista. Pues, aquellos indígenas sintieron la presencia enorme del ejército realista en Puno, en vista de las rebeliones de Tacna (1811) y Cusco (1814); las expediciones argentinas al Alto Perú entre 1811 y 1816 (Bidondo, 1976) y las batallas de Umachiri (1815) y Zepita (1823). Quizá la presencia más significativa fue realizada por el virrey José de la Serna, quien el 19 de agosto de 1823 ingresó a Puno con "cuatro mil hombres y mil caballos" (Archivo Regional de Puno [ARP], 1823: caja 48), recorriendo los pueblos desde Santa Rosa (Ayaviri) hasta Desaguadero, acompañado de colosales tropas virreinales, quienes en sus periplos demandaron exacciones y leva de indígenas.

Las consecuencias de la guerra de Independencia por la presencia del ejército realista y patriota en el sur andino en general y el altiplano puneño, fueron catastróficas en detrimento de las poblaciones indígenas. Aquellas medidas militares ocasionaron la ruptura del orden social andino, la fisura de la estructura económica interétnica, el descenso demográfico, la migración poblacional y el fraccionamiento de los circuitos comerciales interregionales (ARP, 1824: caja 49).

De manera definitoria, la Independencia de Perú fue un proceso largo, complejo y discontinuo, porque como se explica a lo largo del manuscrito, solo trajo cambios superficiales, pero sí muchas brechas sociopolítico-económicas como la desigualdad, la corrupción y la emergencia sanitaria como coyuntura de una guerra que no finaliza (Huanca-Arohuanca, 2020; 2021). En ese criterio, el puneño Juan Bustamante Dueñas, bautizado como el Mundo Purikuq, señala que la declaración de la Independencia es falsa, ya que no ha logrado cambiar ni adelantar nada, por lo que, sin el esfuerzo de todos, Perú está condenado al fracaso (Bustamante, 1849).

\section{Génesis de la Independencia en el altiplano y la rebelión del Cusco}

Siguiendo el paradigma francés, las intendencias fueron circunscripciones territoriales creadas en reemplazo de los corregimientos posterior a la 
rebelión de Tupac Amaru II. La Intendencia de Puno fue creada por la Real Orden del 5 de junio de 1784, estaba integrada por cinco partidos o subdelegaciones (Azángaro, Carabaya, Chucuito, Lampa y Paucarcolla) (Luque, 1999). Por tanto, "el sistema de intendencias creó un nivel administrativo intermedio entre la autoridad del virrey (residente en Lima) y de los corregidores en las provincias (los corregimientos de indios)" (Domínguez, 2017: 16). Posterior a la Independencia de Perú, las intendencias se convirtieron en departamentos, los partidos en provincias y las parroquias en distritos. En ese sentido, el primer prefecto nombrado en Puno fue Pedro Miguel de Urbina y el primer alcalde republicano fue Manuel José Morel.
En otro espacio paralelo a los acontecimientos del altiplano, surgía la rebelión del Cusco de 1814, llamada como la rebelión de los hermanos Angulo, comprendiendo casi la totalidad del territorio sur andino (Cusco, Arequipa, Puno y La Paz). Esa rebelión, que en su inicio fue criolla-urbana, luego incorporó a la masa indígena bajo el liderazgo del cacique de Chinchero Mateo Pumacahua. En consecución, los rebeldes indígenas diseñaron tres expediciones para fraccionar las rutas de comunicación del ejército realista. La primera fue enviada a Ayacucho, la segunda a Arequipa y la tercera hacia Puno y Alto Perú (Aparicio, 1980). Por tanto, el éxito inicial de los rebeldes se debió a la incorporación del cacique de Chincheros (Sala, 1996).

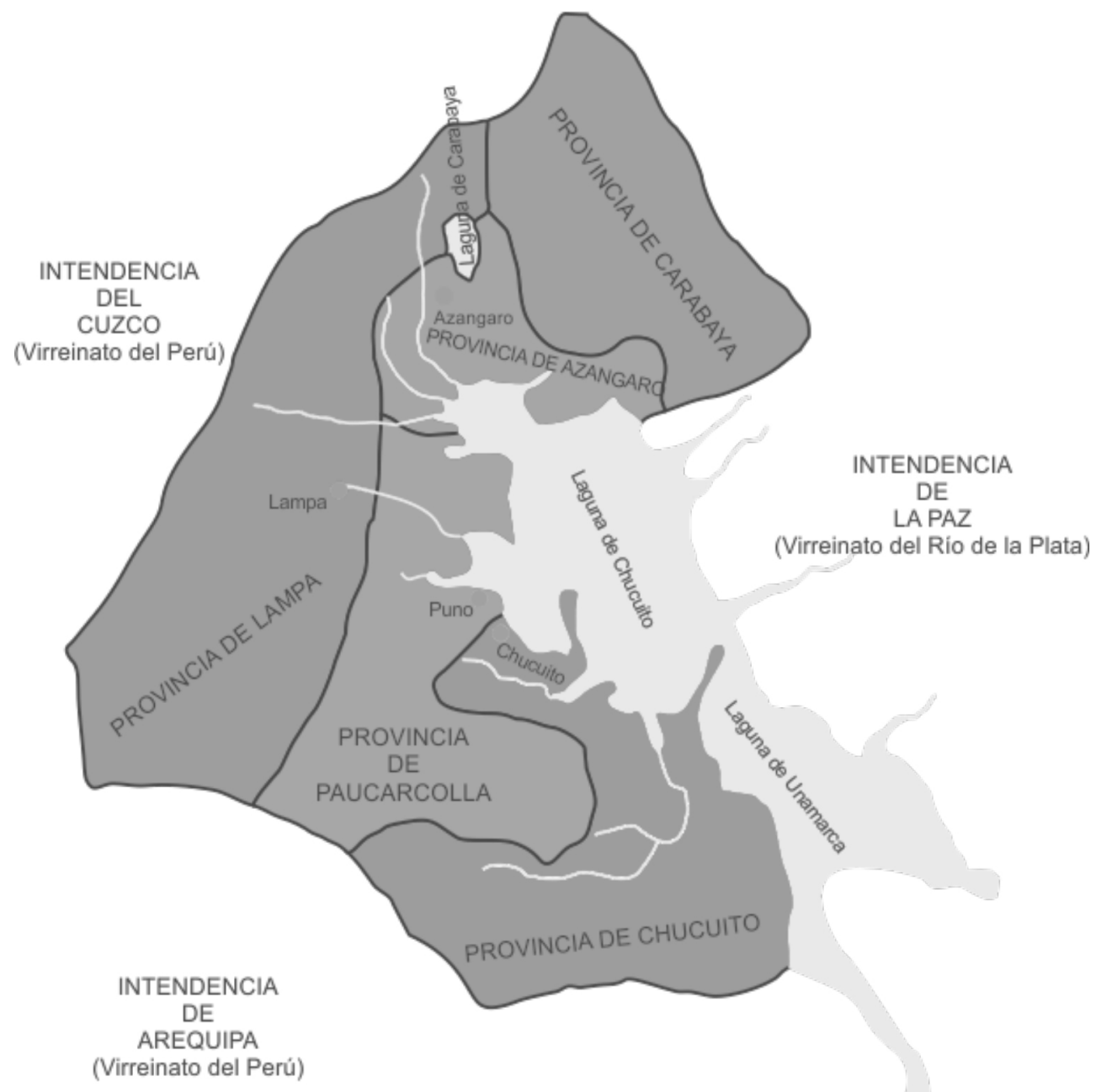

Figura 1. Mapa de la Intendencia de Puno en el virreinato del Perú. Fuente: (Luque, 1999: 244). 
Ya en Puno, los rebeldes logran legitimidad de la masa indígena, es más, el Ayuntamiento Constitucional de Puno logra una alianza con los rebeldes fomentando la huida de las principales autoridades coloniales hacia la ciudad de Arequipa. Los intentos de rebelión eran tan radicales que los mismos sucesos hicieron sentir que se sembraba el odio hacia los españoles, instigando a los criollos contra ellos y que los hombres de la Corona estaban suspicaces y temerosos por la poca religión y hegemonía sobre los indios (Glave, 2015).

Sin embargo, la otra cara de la moneda muestra la participación indígena en la guerra de Independencia como sujetos dominados y frustrados (Soux, 2010). Tal como señala la historiografía local, el dominio y la influencia hacia la masa popular era ejercido por los caciques, quienes debían asegurar su estatus político y económico.

En ese orden de ideas, se presenta al cacique José Manuel Choquehuanca de Azángaro anansa$y a$, que desde el inicio del estado de guerra en el Alto Perú hasta la proclama de Independencia se mantuvo fiel a la causa realista. La subordinación hacia el rey era tan eficiente que, para ello, los indios del altiplano debían entregar la vida por esa causa, tal como Choquehuanca menciona en uno de sus informes:

[...] mandé juntar a son de caja a todos los Naturales de mi gobierno quienes como leales y constantes tributarios que saben servir en medio de sus desdichas al Rey y a los Superiores y aunque estos por la novedad se vieron sorprehendidos pero como entendiesen por tantas y tan diferentes oraciones que les hice en su propio idioma (Archivo General de la Nación, 1811: cuaderno 1170).

Como se observa, la existencia de caciques a favor del rey resulta siendo elemental para la subyugación de los indios. No obstante, existen otros caciques que apoyaron a la rebelión de 1814, tal es el caso del cacique y alcalde de Capachica José Flores, quien junto a 100 hombres se unió al ejército rebelde de Angulo y Pumacahua en la Batalla de Apacheta en Arequipa, asimismo, el cacique de Umachiri Diego Sánchez, el coronel Norberto Dianderas de Santiago de Pupuja y el arequipeño Mariano Melgar, quienes, por apoyar a la rebelión, fueron fusilados después de la batalla de Umachiri.
Posterior a ello, los rebeldes sobrevivientes establecieron su cuartel general en Paucarcolla y nombraron a Tomás Carreri como subdelegado y comandante general de las fuerzas rebeldes del altiplano austral (ARP, 1824).

\section{Consecuencias de la batalla de Umachiri en el altiplano}

El altiplano puneño fue atrio de múltiples batallas por la búsqueda de la libertad. De ahí que resulta fundamental prevalecer la batalla de Umachiri que se llevó a cabo el 11 de marzo de 1815 a orillas del río Llallimayo, donde se enfrentaron las fuerzas rebeldes conformado por miles de indígenas dirigidos por Mateo Pumacahua, Norberto Dianderas y otros; por su parte, el ejército realista estuvo dirigido por Juan Ramírez Orozco, veterano del teatro de guerra en el Alto Perú frente a los patriotas argentinos (De la Pezuela, 2020). Si bien esta batalla constituyó una derrota para los patriotas, los ideales de la justa causa de la Independencia no habían expirado en Umachiri, más bien continuó, sobre todo en el altiplano puneño. Al respecto, el historiador Augusto Ramos (2011) en la perspectiva de los doctores José Antonio Encinas y Eduardo Pineda Arce, sostiene que la batalla de Umachiri no consolidó los deseos del general Ramírez, porque las fuerzas revolucionarias de todo el departamento de Puno se mantenían en pie de guerra. Es decir, en ese espacio altiplánico:

las acciones subversivas se mantuvieron y no sería extraño que muchos de los jefes actuaran sin contacto con Muñecas u otro caudillo, desarrollando espontáneas iniciativas locales que mostraban un estado de ánimo latente inclinado por la protesta, la revancha y la desobediencia (Glave, 2005: 134).

Así como ocurrió con la rebelión de 1780, el sacrificio de los Angulo, Béjar y Pumacahua, no puso fin en Puno a la lucha iniciada por los rebeldes; al contrario, tomó más fuerza, y a lo largo y ancho de su extenso territorio, los hombres que ansiaban su libertad no cejaban en su empeño de morir antes de seguir oprimidos. A su vez, Bernardino Tapia siendo un criollo ilustrado, alentaba a la revolución con la difusión de sus pasquines (Glave, 2005). Por ello, ante la debilidad del Intendente de 
Puno, don Manuel Quimper, fue nombrado en su lugar, el temible sanguinario Francisco Gonzales de Paula que sirvió a Ramírez en toda su campaña contrarrevolucionaria.

Entonces, la lucha por la libertad se hacía notorio cada vez más. Los pueblos subyugados por la Corona española, tales como Puno y Azángaro, se encontraban influenciados por los partidarios de los Angulo y Pumacahua. La provincia de Azángaro se encontraba sublevada con un ejército de 3.000 hombres, al mando de don Cipriano Oblitas, quien al tener noticias de la proximidad de las tropas realistas se replegó hacia Asillo y Orurillo, construyendo trincheras, y en las alturas de Inampo levantaron una verdadera fortaleza en espera de los enemigos, quienes al mando del propio intendente Gonzales iniciaron un combate el día 24 de junio de 1815 . La lucha fue tan sangrienta que murieron más de tres mil patriotas y realistas (Ramos, 2011; Glave, 2015).

El odio de los realistas hacia los patriotas era tan fulminante que se materializó en una carnicería, tal como Encinas declara, "los habitantes de Lequeque fueron pasados a cuchillo, muriendo centenares, y fueron incendiadas sus cabañas, talados sus campos de cultivo y sus habitantes destruidos sin distinción de sexo ni edad" (Ramos, 2011: 57). En ese mismo proceso, la provincia de Huancané también fue escenario de grandes combates, en los que murieron centenares y miles de patriotas, para lo que el Intendente Pío Tristán tuvo que enviar refuerzos desde Arequipa.

Después de esas acciones, cerca de cien prisioneros fueron ejecutados en Puno el día 27 de abril de 1816, entre los que destacan, está el coronel Miguel Pascual San Román que estuvo en Umachiri junto con su hijo Miguel y el prócer cusqueño Santiago Prado, quienes fueron fulminados por las armas el 27 de abril de 1816 en el partido de Lampa y muchos otros ilustres patriotas de todo el departamento de Puno.

\section{Las expediciones argentinas al Alto Perú y la participación puneña}

La población indígena del altiplano estuvo en una encrucijada, no solo como bastión responsable de abastecer a miles de puneños para menguar las expediciones argentinas hacia el Alto Perú, sino también ser parte del soporte económico mediante las contribuciones o donativos obligatorios para sostener al ejército realista de los dos frentes: en la revolución del Cusco y las guerras en el Alto Perú.
Es más, en Puno estuvo una de las milicias indígenas realistas denominado Río de la Plata, dirigido por el cacique Manuel José Choquehuanca. De manera que entre 1811 y 1816 el espacio de alzamiento comprendía los virreinatos del Perú y Río de la Plata, siendo el escenario principal el altiplano sur andino. Asimismo, en ese espacio insurgente confluía la "población criolla, mestiza e indígena buscando incursionar en tierras altiplánicas donde había una gran cantidad de indígenas que se hallaban en estado de insurgencia, pero cuyos centros poblados y ciudades se encontraban controladas por el ejército virreinal del Perú" (Soux, 2016: 460-461).

Consciente del gran peligro que representaba la insurgencia en el Alto Perú, el intendente de Puno, Manuel Quimper, fortaleció los puestos de Desaguadero y Huancané para impedir que la sublevación traspasara las fronteras de Charcas y el Bajo Perú. Ya que la ruta a Arica se hallaba también controlada por los rebeldes, lo que hacía imposible para el ejército virreinal comunicarse con el ejército de Goyeneche que se hallaba en Potosí y Cochabamba (Soux, 2016).

Conforme con los primeros enfrentamientos entre la primera expedición argentina hacia el Alto Perú dirigida por Castelli y el ejército real del Alto Perú comandada por José Manuel Goyeneche, es donde se desarrolló la batalla de Guaqui o Batalla de Yuraicoragua, realizado el 20 de junio de 1811. En esa batalla participó el batallón de Milicias de Puno, dirigidas por Mario Lechuga y el escuadrón de milicias de Azángaro dirigido por José Manuel Choquehuanca. El resultado fue triunfo realista, debido a esta acción Goyeneche será condecorado con el título nobiliario de Conde de Guaqui. Tal como se muestra en el siguiente documento:

Por quanto el M.J. señor general en jefe del ejército el brigadier Don José Manuel de Goyeneche, imparte al gobierno la plausible noticia de la gloria de nuestras armas en el pueblo de Guaqui en cuyo punto habían reunido sus fuerzas los insurgentes del Reyno de Buenos Aires, los que vil y cobardemente abandonaron aquel punto fatigado de nuestros fuegos, dejándose el tren de campaña compuesto de quince piezas de cañón, el almacén de municiones, quatrocientos fusiles, y una completa botica, cerca de trescientos prisioneros con la crecida perdida de quinientos muertos 
resultando de nuestra parte en corto número que es a indispensable, que por su valor y constancia hicieron el sacrificio de sus vidas, a Dios, el Rey y la patria, cuya memoria de su honor y valor, será eterna en los annales de nuestra historia (ARP, 1811: caja 36).

Posterior a los sucesos de Guaqui, hubo varias conflagraciones en el Alto Perú entre los patriotas y realistas. La población indígena puneña organizada en cuerpo de milicias naturales tuvo destacada participación a favor de los realistas. Siendo uno de esos enfrentamientos la Batalla de Salta, realizado el 20 de febrero de 1813, donde se enfrentaron las fuerzas patriotas del Ejército del Norte, al mando del general Manuel Belgrano, y los realistas, conducidos por el general Pío Tristán. La contienda, que se desarrolló en los campos de Castañares, decidiéndose finalmente a favor de las tropas patriotas.

Pero como en toda guerra que busca la libertad, existen miles de vidas perdidas, la Independencia de Perú no fue la excepción, porque mucha gente murió sin saber el real desarrollo y propósito de la guerra (Soux, 2010). Como sucedió con los indígenas que eran usados por los realistas como blasones de contención hacia el enemigo que avanza en la búsqueda del indeterminismo material.

\section{El virrey José de la Serna en Puno}

José de la Serna y Martínez de Hinojosa (17701832) llegó al Perú en 1816 como general en jefe del ejército del Alto Perú. Después del motín de Aznapuquio, debido a las diferencias estratégicas acerca de la guerra en el Alto Perú con Joaquín de la Pezuela, asume el cargo de virrey. En ese paralelismo, llegaba al Perú la expedición de San Martín a la costa peruana, y posterior a ello viene la ocupación y el temor social de la capital del virreinato del Perú. Por ello La Serna abandonó Lima el 5 de julio de 1821 rumbo al valle del Mantaro (Huancayo) y cuatro meses más tarde recibió una invitación de la Real Audiencia del Cusco para que establezca su gobierno en dicha ciudad, a la que llegaría el sábado 29 de diciembre de 1821 .

$\mathrm{Al}$ respecto se dice que:

[...] el Perú pasó a tener entonces un gobierno patriota en Lima, encabezado por el protector San Martin, y un gobierno realista, en el Cusco, liderado por el Virrey
La Serna, el cual controlaba más de la mitad del virreinato y, sobre todo, el territorio de la sierra sur y sus recursos naturales" (O'Phelan, 2014: 335).

De esa manera, Cusco y el altiplano austral se convirtieron en el epicentro de la resistencia realista en la guerra de Independencia.

\begin{abstract}
La Serna se trasladó al Cusco "con su guardia personal, la compañía de Granaderos de Burgos, y dos cañones [...]. Además, llevó consigo la imprenta para publicar periódicos e influenciar sobre la opinión pública, así como, estableció la Casa de Moneda debido a los activos ingresos de las provincias de Cusco y Puno (O'Phelan, 2014: 336-337).
\end{abstract}

No obstante, la inicial lealtad que ofrecieron las autoridades cusqueñas y las elites regionales se iría desgastando debido a que La Serna comenzaba a exigir sucesivas donaciones y contribuciones forzosas, con el fin de mantener activo y bien abastecido al ejército realista (O'Phelan, 2014; Quispe y Quispe, 2019).

En cuanto a los sucesos que convocan al estudio, el virrey La Serna ingresó a la Intendencia de Puno el 19 de agosto de 1823. Previo a la Batalla de Zepita, envió una orden circular a los alcaldes de los pueblos de Santa Rosa, Ayaviri, Pucará, Calapuja, Juliaca, Paucarcolla y Puno. Como en esas coyunturas la hegemonía del virreinato era inmenso, las autoridades no tenían otra opción que cumplir con la petición.

Los alcaldes de los pueblos del tránsito de Santa Rosa a Puno tendrán pronto en las pascanas que al margen indica víveres para quatro mil hombres y forrajes para mil caballos en los días que se expresan y vajo toda responsabilidad, en la inteligencia que no ha de haber falta alguna ni de víveres ni forrajes. De quedar enterados de esta orden circular firmarán los alcaldes de cada pueblo a continuación, y el conductor seguirá la marcha a Puno (ARP, 1823: caja 48).

Además, La Serna durante su estadía en Puno efectuó diversas actividades de carácter militar, pero a la par realizaba gran difusión periodística para 
influenciar en la opinión pública, por ello remitió al Intendente de Puno ejemplares de la Gaceta de gobierno número 31 donde señala "el apresamiento de la fragata enemiga Azarvia en el puerto de Pisco, y el parte del jefe político de Huancavelica sobre el enemigo", donde indica que "las haga circular en la provincia de su mando y se introduzca en las partes ocupadas por los rebeldes" (ARP, 1823: caja 48).

De modo concluyente al apartado, después de la batalla de Zepita realizado el 25 de agosto de 1823, La Serna emprendió una persecución hasta Santiago de Machaca (Bolivia) al ejército patriota de Santa Cruz y Agustín Gamarra, ocasionando la desarticulación de su ejército. A ese episodio se conoce en la historiografía como la Campaña del Talón. Posterior a los sucesos descritos, La Serna regresó a Puno y estableció su Cuartel General en Lampa y desde allí mantuvo la hegemonía política hacia los pueblos subyacentes (Sobrevilla, 2015).

\section{El libertador Simón Bolívar en Puno}

El libertador de Venezuela, después de emprender la campaña final en el Perú con las victorias de Junín y Ayacucho, realizó su recorrido triunfal por los Andes meridionales del Perú. Previamente, Sucre preparó la salida del ejército libertador del Cusco rumbo al Alto Perú, "movilizando a la legión peruana y el batallón Nro. 2 del Perú con mil hombres más 550 húsares de Junín” (Rincones, 2014: 235).

La historia local visualiza que Sucre debió estar en Puno entre el 29 de enero y el 3 de febrero de 1825. Tal como afirma el notable abogado puneño Eduardo Pineda (1922):

El 1 de enero de 1825, se reunió la municipalidad para ocuparse de la recepción de tan ilustre huésped y, también del alojamiento para los cuatrocientos soldados que venían con él. Los respetables miembros acordaron acuotarse hasta reunir la suma de 2000 pesos, y que se embargasen todos los cebadales existentes para el forraje de la caballería (Pineda, 1922: 4).

En su estadía en el mencionado departamento, Sucre comunicó a Bolívar que había elaborado el decreto "que anuncia y prepara el nacimiento de la futura República de Bolivia" (Rincones, 2014: 238). También se conoce que en la villa de Acora, Sucre y Casimiro discutieron largamente el problema del Alto Perú y durante su itinerario por Zepita se conmemoró la batalla del 25 de agosto de 1823 . En tal sentido:

[...] el prefecto y la municipalidad de Puno rindieron homenaje a Sucre por los menos durante tres días con jolgorio y algarabía, para ello nombraron una comisión de festejos dirigidos por don Vicente Rodríguez, don Blas Ramos y don Leandro Cuentas sujetos de honor, quienes desempeñarán completamente sobre el particular, quedando ese cuerpo en todo lo posible (ARP, 1825: caja 01).

De manera que Bolívar, en su recorrido por los pueblos australes, atravesó en dos ocasiones el departamento de Puno, en la primera travesía recorrió de Arequipa hacia Cusco y en la segunda oportunidad transitó de Cusco al Alto Perú. En consecuencia, Bolívar estuvo en Puno el 5 de agosto de 1825 (Urviola, 2013) y para su llegada las primeras autoridades republicanas realizaron actividades y coordinaciones, por lo que el 6 de julio de 1825 se dio a conocer la relación de curas y vecinos notables que lo hospedarían en su visita a Puno, por ejemplo: en el pueblo de Santa Rosa, los anfitriones fueron los curas de Ayapata, Phara y Quiaca; en Ayaviri, los curas de Coasa, Macusani y San Antón; en Pucará, los curas de Arapa, Caminaca, Taraco y Pusi; en Juliaca, el cura de Moho-Capachica; y en Puno, el primer día el cura de Asillo, el segundo día los curas de Puno y Chucuito, el tercer y cuarto día el vecindario de Puno y el quinto día nuevamente el cura de Capachica (ARP, 1825: caja 01).

En consecución, en el ARP (1825: caja 01) se manifiesta que el libertador del norte, en cuanto a cuestiones sociopolíticas, emitió decretos tales como:

- La declaratoria como pueblos heroicos y vitalicios a los distritos de Umachiri, Llalli, Cupi, Macarí y Santa Rosa, lugares que desde entonces celebran su aniversario de fundación política.

- La incorporación eclesiástica de los partidos de Chucuito y Huancané a la jurisdicción del obispado del Cusco (7 de agosto de 1825).

- La eliminación del título de Caciques y la distribución de tierras a los indios. 
- La construcción de caminos desde el puente Maravillas (Juliaca) con dos ramales rumbo a Arequipa y Cusco respectivamente.

- La creación del Colegio de Ciencias y Artes en Puno.

De manera que uno de los decretos más importantes, sin duda, fue la creación del Colegio de Ciencias y Artes, y los ingresos económicos de los diezmos de las provincias de Chucuito y Huancané, fueron el sostén para el funcionamiento del citado centro educativo que serviría en cierto sentido para conocer más de cerca los acontecimientos de la época y para reforzar las narrativas oficiales como reconstrucción positiva del Estado-nación en el Perú (Turra et al., 2018; Cavieres-Fernández et al., 2020; Cerda y Díaz, 2020). Puesto que, la transición de la Colonia a la República tenía un rasgo fundamental, que fue el de fomentar la educación de los indígenas, así como señala Guillermo Miller: "el medio es ilustrar en lo posible a la casta indígena y que ella entre en el goce de la ciudadanía" (ARP, 1825: caja 02).

\section{Situación económica de Puno entre 1815 y 1825}

La Independencia de Perú tuvo un costo económico muy alto para el país, en esa línea Orrego (2011: 1) sostiene que: "dos ejércitos -unos 20 mil hombres- transitaban por el país. Había que alimentarlos, vestirlos, armarlos y pagarles. El dinero y los productos para sostenerlos salieron de los propios peruanos". No obstante, este esfuerzo económico no reflejó un cambio estructural posindependencia. En ese sentido, Niels Jacobsen (2013) y Carlos Contreras (2011) coinciden en señalar que la Independencia no trajo cambios estructurales en el aspecto social y económico.

La tragedia de la Independencia en el Perú, está en que ese cambio político no sucedió. Las haciendas, los esclavos y las minas cambiaron de manos, pero no de espíritu ni de hábitos. Salieron de las manos de comerciantes y empresarios "chapetones" y fidelistas, para entregarse a las de generales y caudillos criollos y mestizos [...] sin que se alterase la estructura social del país. Estos ocuparon el lugar de aquéllos, sin que su preparación o su motivación ofreciesen un mejor desempeño económico. La esclavitud se mantuvo por treinta años más, los latifundios y las minas no cambiaron su método de producción [...] (Contreras, 2011: 6).

Para el caso del Altiplano austral en general y Puno en particular, la depresión económica se había iniciado con la gran rebelión de Tupac Amaru II. Por ello, se sostiene que las urbes fueron deshabitadas y destruidas. Además, "la baja enorme de la población ganadera y la disminución del capital pecuario fue imposible reemplazar en el mediano plazo" (Tamayo, 1982: 74-75). En consecuencia, Puno llega a la Independencia en plena etapa de depresión económica y de crisis generalizada. Para contrastar esa aguda situación económica de Puno, Choquehuanca (1833) indica que Azángaro en 1829 se encontraba en:

completa decadencia [...]. Las carestías generales han sido tremendas y han hecho estragos en la población; con la carestía general de 1814 y 1816 murieron centenares de personas; las plazas, las calles y los campos estaban sembrados de cadáveres de los habían sucumbido al hambre [...]. La industria y el comercio están en la mayor decadencia por falta de capitales, por escases de bestias de transporte y la educación está totalmente abandonada (Choquehuanca, 1833: 59).

Como ya se mencionó, el panorama fue desolador en el altiplano puneño. Al respecto, existen testimonios preocupantes, así, por ejemplo, el 7 de enero de 1818, el Recaudador de San Antón (Azángaro), don Carlos Tutacano Morales informa "no poder cumplir con la contribución de naturales debido a la calamidad en que se encuentra dicha población" (ARP, 1818: caja 44). Asimismo, el alcalde de Moho en 1817, Manuel Isidro Olvea invoca paralizar la construcción de la cárcel debido a la hambruna que afecta a la población, bajo los siguientes términos.

La plaga, que oprime de hambres a este mi comando de indios, repido a su piedad paternal, mande al pedáneo de este pueblo suspenda aun la construcción de la cárcel de que apura a los miserables indios, pero 
debiendo ser, una obra maciza, fuerte y duradera para la custodia de reos, no son capaces los indios lánguidos y extenuados de fuerzas, de poner en logro su trabajo, pero si para estar siquiera con descanso en el día, y mas no teniendo abios. Con que alimentarse fuera de ellas, quando ni aun, yo tengo que darle a proporción; para que los indios al comer, se equiparan con los cuadrúpedos, y por eso la escasez presente, hace más efecto en ellos (ARP, 1817: caja 41).

Por consiguiente, el aporte económico de Puno para sostener las tropas reales fue considerable y fundamental, ya sea en forma de tributos, contribuciones, acotaciones forzosas en dinero, capital humano y logístico, como a continuación se demostrará: el virrey del Perú, Joaquín de la Pezuela con fecha 22 de agosto de 1816, envía un circular a los gobernadores intendentes indicando "desde que se restableció el ramo de tributos con el nombre de contribución se mandaron hacer en todos los partidos del distrito de este virreinato padroncillos provisionales, [...] siendo estos documentos esencialísimos para la cuenta general del ramo" (ARP, 1816: caja 40). Para mayor información, en la tabla a posteriori se analizará la contribución.

Las contribuciones de indígenas durante las guerras de Independencia fueron cumplidas con muchos obstáculos, ya sea en dinero o en especies. Se conoce que los tributos se pagaban en dos armadas: durante el semestre de San Juan y el semestre de Navidad. Según el informe realizado por el subdelegado Francisco de Paula Mendizábal, la contribución de los pueblos del partido de Chucuito fue de 27.323.4 $1 \frac{1}{2}$ pesos que corresponden al semestre de San Juan (ARP, 1818). A medida que pasaban los años, la situación del virreinato se complicaba, debido a esas circunstancias, las autoridades virreinales, para incrementar los ingresos de la real hacienda, implementaron un conjunto de medidas económicas afectando fundamentalmente a los indígenas, aparte de sus tributos, ahora tenían que pagar: contingentes mensuales extraordinarios, donativos, $5 \%$ de las ventas de tierras, contribución del $10 \%$ de las fincas de comunidad, etc. Esas medidas arruinaron la precaria economía rural de Puno (ARP, 1823).

Asimismo, el 31 de enero de 1821, desde Lima, el virrey La Serna solicitó 800 reclutas a la Intendencia de Puno, como señala el siguiente documento:

[...] siendo de la más urgente necesidad, aumentar el ejército por el grado de fuerza con que pueda no solo garantizar la seguridad del virreynato, sino también arrojar al enemigo invasor he determinado pedir reclutas a las provincias interiores que $\mathrm{Ud}$. Manda he señalado ochocientos que deberán hacerse con la más urgente prontitud [...] (ARP, 1821: caja 47).

En términos menos complejos, los indígenas no solo estaban condenados a contribuir económicamente, como cuando el 21 de julio de 1823 el virrey La Serna ordena que el pueblo de Lampa contribuya con dos mil pares de calzados en tan solo quince días (ARP, 1823), orden que sin duda

Tabla 1. Contribución de los pueblos del partido de Chucuito en 1818.

\begin{tabular}{lccc}
\hline \multicolumn{1}{c}{ Pueblos } & Cantidades & Premios & Líquido \\
\hline Chucuito & 2125 & 89 & 2040 \\
Acora & 5596 & 223.7 & 5372.1 \\
San Miguel de Ylave & 2254.4 & 89 & 2136.4 \\
Santa Bárbara de Ylave & 2202.4 & 88 & 2114.4 \\
Juli & 3232.6 & 129.2 & $3103.31 \frac{1}{2}$ \\
Pomata & 4353 & 174.1 & 4178.7 \\
Asunción Patrón de Yunguyo & 2268 & 90.5 & 2177.3 \\
Magdalena de Yunguyo & 1500 & 60 & 1440 \\
Zepita & 3232 & 129.2 & 3102.6 \\
Desaguadero & 0848.6 & 33.6 & 815 \\
Pichacani & 878 & 35 & 843 \\
Total & & & $27.323 .41 / 2$ \\
\hline
\end{tabular}

Fuente: ARP, Fondo intendencia 1818: caja 44. 
es una coacción vertical. Ahora, los indígenas estaban obligados a combatir en el frente de batalla, a morir en guerra y, lo peor, muchos de ellos no sabían exactamente por qué combatían.

\section{Situación social de Puno durante la Independencia}

La Intendencia de Puno durante el 1812 contaba con una población de 184.682 habitantes, de estos 10.000 eran españoles, 14.000 eran reconocidos como mestizos y 160.682 eran indígenas que permanecieron como la base estructural de una guerra por la libertad (Chanamé, 2015). Es más, Puno era la cuarta Intendencia más poblada del virreinato, solo superada por Cusco, Tarma y Trujillo. Mientras que "para el año 1828, periodo de la república inicial, Puno tenía una población de 156.450 habitantes" (Chanamé, 2015: 221). En efecto, Puno en ese lapso de 16 años reportó un descenso demográfico de 28.232 habitantes.

La población puneña durante los años de 1815 y 1825 se vio seriamente afectada por un conjunto de obligaciones que cumplir tanto para el ejército realista como al patriota. Con la rebelión del Cusco de 1814, y posteriormente con la batalla de Umachiri, las estructuras de poder andina-llámese autoridades comunales, caciques o curacas y jilacatas- fueron removidas según el grado de participación en dicha rebelión. Las nuevas autoridades nombradas, lógicamente los que apoyaron la causa realista, gozaban de prestigio y poder, ocasionando rivalidades con las legítimas autoridades nombradas por consenso en los ayllus.

Aparte de ello, las múltiples obligaciones que tenían que cumplir las poblaciones puneñas arruinaron la economía rural y campesina de esos pueblos. Entre las obligaciones más comunes que cumplían esas gentes fue: abastecer de miles de reclutas al ejército español, proporcionar dinero y alimentos para los ejércitos realistas/patriotas, trasladar los materiales de guerra de distintos puntos del escenario de guerra, cumplir con las obligaciones tributarias de contribuciones o donaciones forzosas, cumplir con el servicio personal de pongos y muleros a los curas, etc. Todas esas obligaciones ocasionaron ostensiblemente el descenso demográfico forzado de la población indígena (Díaz et al., 2021).

De ahí que uno de los puntos polémicos del proceso de Independencia es la participación popular. Indudablemente, aquella cooperación popular fue muy activa y decisiva, los bandos estaban conformados de indígenas, en las tropas españolas como en las tropas libertadoras, y siempre como súbditos, pero nunca como líderes. "Lo que más bien parece que ocurrió fue una gran guerra civil en la que los distintos sectores sociales del país tuvieron la oportunidad de combatir sobre la base de intereses singulares (étnicos, clasistas, regionales, etc.)" (Fonseca, 2016: 82). No obstante, la historiografía tradicional legitimaba, por medio de los textos escolares durante el siglo XIX y principios del XX, la tesis de la Independencia conseguida, porque sostenían que la voluntad general de todos los habitantes estaba decidida por la Independencia, sin embargo, esta voluntad no había sido suficiente porque Perú era el centro de poder español, consecuentemente, los patriotas peruanos necesitaban de la ayuda de ejércitos extranjeros (Espinoza, 2012; Chaupis, 2015).

Al mismo tiempo, cuando se analiza la memoria social subversiva que había experimentado la población rural puneña durante la rebelión de Túpac Amaru II, esta se mantuvo intacta, tal como afirma Montoya (2019): "no estaba desinformada la plebe rural en el sur andino. Aunque con distorsiones, los disidentes ponían en movimiento ideas y aspiraciones abiertamente subversivas" (Montoya, 2019: 189).

Asimismo, esta visión tradicional admitía que la Independencia fue un proceso nacional multiétnico, resultado de una toma de conciencia colectiva, guiada por los precursores o ideólogos de la Independencia. Pero de manera definitoria se sostiene que: "el Perú colonial no estuvo compuesto de peruanos. Esa sociedad fue altamente estratificada y diferenciada, y sus líneas de separación y de oposición fueron trazadas a partir de criterios económicos, raciales, culturales y legales" (Bonilla, 2016: 55). Y los círculos intelectuales eran mínimas como para poder influir en una población de mayoría analfabeta. Situación que hoy convoca a corregir los errores de otros, dentro del compromiso profundo plasmado a dar debate a los acontecimientos en cuestión.

\section{Conclusiones}

Estando en el espacio del debate transitorio del Virreinato a la República, se considera que la mejor forma de analizar los acontecimientos caleidoscópicos en torno a los ejes sociopolítico-económicos en el altiplano puneño, surge mediante las narrativas 
de los propios actores ubicados en el ARP y otras fuentes biconvexas a la Independencia de Perú. Es más, cuando un debate como este se produce en torno al Bicentenario de la Independencia que se dará a lugar el 2021 en un país asaltado por la corrupción y la pandemia mundial, el conjunto de posibilidades para los pueblos subalternos como el altiplano austral se reduce a niveles microscópicos, como pasó en los siglos XIX y XX. Solo volver a la cuestión umbral de los pueblos originarios con historia, hará que mejore las dicotomías existentes, los fenómenos sociales negativos, el silencio al que los pueblos altiplánicos están sometidos y otros patrones de dominación creados por las hegemonías imperantes del Occidente.

A continuación se hace alcance de los tres horizontes debatidos en el manuscrito. A nivel político administrativo, Puno durante la Independencia (1815-1825) pertenecía a la Intendencia de Puno, que se encontraba dividida en cinco partidos o subdelegaciones (Azángaro, Lampa, Carabaya, Chucuito y Paucarcolla), y estos a su vez en pueblos o parroquias. Asimismo, fue acompañado por la presencia de grandes personajes que tuvieron una enorme influencia en la Historia de Perú, los que se mencionan de la siguiente manera: Bolívar, Sucre, La Serna, Pezuela, Santa Cruz, Pumacahua y los Hermanos Angulo. Personajes insignes que participaron en una serie de batallas alrededor del altiplano según sus intereses políticos.
En el nivel económico, la Independencia no trajo cambios estructurales para los indígenas que habían luchado para ello. Mas, por el contrario, imperó la esclavitud, el racismo, el odio al indio y la subsunción hacia los habitantes del altiplano porque los contrarrevolucionarios no tenían ni un ápice de moralidad. Más aún, la nación altiplánica contempló la depresión económica iniciado con la gran rebelión de Tupac Amaru II, agudizado por la rebelión del Cusco de 1814 y las guerras del Alto Perú que llevaron a una crisis generalizada. De ahí que el sistema de despojo se materializó en forma de levas y exacciones contra los indígenas ocasionados por ambos grupos antagónicos.

En definitiva, a nivel social, las estructuras andinas de poder fueron debilitadas debido a la ambivalencia de los indígenas que no encontraban, por la presión de los militares, si optar por rendir fidelidad a los realistas o a los patriotas. Es más, las imposiciones de los realistas ocasionaron ostensiblemente la dispersión y el descenso demográfico de la población puneña. Como se pone a flote en lo siguiente: para 1812 Puno tenía 184.682 habitantes, sin embargo, para 1828 solo tenía 156.450 habitantes, esto hace sospechar que, el hecho de abastecer a miles de reclutas del ejército realista, proporcionar dinero, alimentos y trasladar los materiales bélicos de distintos puntos del escenario de conflagración, fulminó la naturaleza de los hombres del altiplano.

\section{Referencias Citadas}

Aparicio, M. J.

1980 "Conspiraciones y rebeliones en el siglo XIX", Volumen 8, "La revolucion de Cusco de 1814". En Coleccion Documental de la Independencia del Perú (Tomo II). Comisión nacional del sesquicentenario de la independencia del Perú, Lima.

Bidondo, E.

1976 La guerra de la Independencia en el Norte Argentino (Segunda Ed). EUDEBA, Argentina.

Bonilla, $\mathrm{H}$.

2016 Metáfora y realidad de la independencia en el Perú (6a Edición). IEP, Lima.

Bonilla, H. y Spalding, K.

1981 "La independencia del Perú: Las palabras y los hechos". En H. Bonilla (Ed.), La independencia del Perú (Segunda ed, pp. 70-114). IEP, Lima.

Bustamante, J.

1849 Apuntes y observaciones civiles, políticas y religiosas con las noticias adquiridas en este segundo viaje a la Europa. Imprenta de Lacrampe Son y Compañía, Paris.

Cavieres-Fernández, E. et al.

2020 "Textos escolares chilenos y peruanos y sus narrativas sobre participación ciudadana durante las independencias nacionales. Implicancias para la formación ciudadana". Diálogo Andino, 63, 271-283.

Cerda, K. y Díaz, A.

2020 "Historia y Ciencias Sociales en tiempos de crisis". Diálogo Andino, 61, 3-5.

Chanamé, R.

2015 La república inconclusa (Tercera Ed). Derrama Magisterial, Lima.

Chaupis, J.

2015 Los textos escolares en conflicto con la subalternidad: la Guerra del Pacífico en las aulas. Diálogo Andino, 48, 99-108.

Choquehuanca, J. D.

1833 Ensayo de estadística completa de los ramos económico políticos de la provincia de Azángaro en el departamento de Puno de la república peruana, del quinquenio contado desde 1825 hasta 1829 inclusive. De M. Corral, Lima.

Contreras, $\mathrm{C}$.

2011 October 7. "Independencia sí, Revolución no”. Laicacota. http://laicacota.blogspot.com/2011/10/peru-independenciay-economia-1810-1825.html 
De la Pezuela, J.

2020 "Compendio de los sucesos ocurridos en el Ejército del Perú y sus provincias (1813-1816)”. En Población y sociedad. Proyecto Especial Bicentenario. Perú.

De la Puente, J. A.

1970 Notas sobre la causa de la independencia del Perú. (Segunda Ed). Studium, Lima.

Díaz, I. et al.

2021 "Espacios campesinos indígenas y estancias coloniales: el caso de Santa Cruz (Valle Viejo, Catamarca, Argentina). Siglos XVI-XVIII. Primeros resultados". Diálogo Andino, 64, 139-149.

Domínguez, N.

2017 April 22 ¿Desde cuándo existe la "unidad regional” de Puno? Noticias SER.PE, 2017. http://www.noticiasser.pe/index. php/opinion/desde-cuando-existe-launidad-regional-de-puno

Escanilla, S.

2013 La transformación política de la sociedad virreinal. La guerra de independencia en el Perú 1820-1824. XIV Jornadas Interescuelas/Departamentos de Historia. Departamento de Historia de la Facultad de Filosofía y Letras. Universidad Nacional de Cuyo, Mendoza.

Escanilla, S.

2018 "Hacia una nueva cronología de la Guerra de independencia en el Perú". En CarmenMcEvoy and Alejandro Rabinovich (Ed.), Tiempo de guerra: Estado, nación y conflicto armado en el Perú, siglos XVII-XIX (pp. 111-137). IEP, Lima.

Espinoza, A.

2012 "La Independencia en los textos escolares peruanos, 1821-c. 1921”. En C. McEvoy (Ed.), En el nudo del imperio. Independencia y democracia en el Perú (pp. 395-416). Instituto de Estudios Peruanos / Instituto Francés de Estudios Andinos, Lima.

Fonseca, J.

2016 “Bandoleros o patriotas? Las guerrillas y la dinámica popular en la independencia del Perú”. In A. Loayza (Ed.), La Independencia peruana como representación historiográfica, conmemoración y escultura publica (pp. 81-99). IEP, Lima.

Glave, L. M.

2005 "La llustracion y el pueblo: el "loco" Bernardino Tapia. Cambio y hegemonia cultural en 10s Andes al fin de la colonia. Azangaro 1818". Tiempos de América: Revista de Historia, Cultura y Territorio, 12, 133-149. https://www. raco.cat/index.php/TiemposAmerica/article/view/105661

Glave, L. M.

2015 "Guerra, política y cultura en la génesis de la independencia andina 1808-1815". In C. Contreras \& L. M. Glave (Eds.), La Independencia del Perú: ¿Concedida, conseguida, concebida? (Primera Ed, pp. 305-354). IEP, Lima.

Huanca-Arohuanca, J. W.

2020 "Caleidoscopio social al Covid-19: pánico y desesperación en tiempos de aislamiento". Revista Universidad y Sociedad, 12(6), 226-231.

Huanca-Arohuanca, J. W.

2021 "Narrativas de guerra y resistencia: participación de la mujer austral del Perú en la Guerra del Pacífico". Encuentros. Revista de Ciencias Humanas, Teoría Social y Pensamiento Crítico, 13, 50-59.

Huanca-Arohuanca, J. W. y Pilco, N.

2021 "Acciones revolucionarias en Ámérica Latina: Puno y el Alto Perú durante el proceso de independencia (1809-1825)". Chakiñan. Revista de Ciencias Sociales y Humanidades, 14.
Jacobsen, N.

2013 Ilusiones de la Transición. El Altiplano Peruano, 17801930. BCRP, Perú.

Loayza, Alex.

2016 La independencia peruana como representación. Historiografía, conmemoración y escultura pública. IEP, Lima.

Luque, $\mathrm{M}$.

1999 "La Intendencia de Puno: de circunscripción colonial a departamento de la República del Perú (1784-1824)". Revista Complutense de Historia de América, 25, 219-252.

Méndez, C.

2014 La República Plebeya: Huanta y formación del Estado Peruano, 1820-1850. IEP, Lima.

Montoya, G.

2019 La independencia controlada: Guerra, gobierno y revolución en los andes. Sequilao Editores, Lima.

Morán, D. y Carcelén, C.

2019 "'Sojuzgar las capitales para que pueda cesar la alteración y el incendio'. La guerra de propaganda en la prensa de Lima y Buenos Aires en tiempos de la Independencia (1810-1816)". Fronteras de La Historia, 24(2), 40-78.

O'Phelan, S.

1987 "El mito de la independencia concedida, los programas políticos del siglo XVIII y del temprano XIX en el Perú y el Alto Perú". En A. F. Galindo (Ed.), Independencia y Revolución (1780-1840) (Tomo 2, pp. 5241-5244). Instituto Nacional de Cultura, Lima.

O'Phelan, S.

2014 La Independencia en los Andes. Una historia conectada. Fondo Editorial del Congreso del Perú, Lima.

Orrego, J. L.

2011 October 7. "La Independencia y su costo económico". Laicacota, 6-8. aicacota.blogspot.com/2011/10/peruindependencia-y-economia-1810-1825.html

Pineda, E.

1922 September 16. "La llegada del gran Mariscal Sucre a Puno". El Siglo, N 2079.

Quispe, C., y Quispe, A.

2019 Las principales acciones de gobierno de José de la Serna durante el gobierno virreinal: Cusco entre 1821-1825. Universidad Nacional de San Antonio Abad del Cusco.

Ramos, A.

2011 Bocetos históricos de la provincia de Melgar. Dasur Graff, Puno.

Rincones, $\mathrm{O}$.

2014 Ayacucho y la Independencia del Alto Perú. Instituto Internacional de Integración, La Paz.

Sala, N.

1996 Y se armó el Tole-tole. Tributo indígena y los movimientos sociales en el Virreynato del Perú, 1784-1814. Instituto de Estudios Regionales "José María Arguedas", Ayacucho.

Sobrevilla, N.

2015 Andrés de Santa Cruz, caudillo de los Andes. PUCPIEP, Lima.

Soux, M. L.

2016 De cercos, masacres e insurgencia de larga data. La Paz en 1811 y 1814 en el contexto de una guerra continental. En S. O'Phelan (Ed.), 1814: La junta de gobierno del Cuzco y el sur andino (pp. 459-482). IEFEA, PUCP, Lima.

Soux, M. L.

2010 El complejo proceso hacia la independencia de Charcas (1808-1826). Guerra, ciudadanía, conflictos locales y 
participación indígena en Oruro. Institut français d'études andines.

Tamayo, J.

1982 Historia Social e indigenismo en el Altiplano. Ediciones Treintaitres.

Turra, O. et al.

2018 "Identidad cultural indígena en el discurso pedagógico de la historia. Una mirada al currículum latinoamericano". Diálogo Andino, 57, 49-60.

Urviola, L.

2013 Bolívar en Puno y otros ensayos bolivarianos. Corporación MERU, Puno.

\section{Archivos y fuentes primarias}

Archivo General de la Nación.

1811 Libro de Superiores Decretos de 1807 a 1812. Ministerio de Hacienda y Comercio H-3, Carpeta N 327, Cuaderno 1170.
Archivo Regional de Puno [ARP].

1823 Fondo intendencia, documento varios. 21 de julio. Caja 48. Folio 1.

ARP. 1811 Fondo intendencia, documento varios. s/f. Caja 36. Folio 2.

ARP. 1816. Fondo intendencia, documento varios. s/f. Caja 40. Folio 1.

ARP. 1817. Fondo intendencia, documento varios. s/f. Caja 41. Folio 1.

ARP. 1818. Fondo intendencia, documento varios. s/f. Caja 44. Folio 2.

ARP. 1821. Fondo intendencia, documento varios. s/f. Caja 47. Folio 2.

ARP. 1824. Fondo intendencia, documento varios. 4 de julio. Caja 49. Folio 2.

ARP. 1825. Fondo prefectura, documento varios. s/f. Caja 01-02. Folio 1-2. 